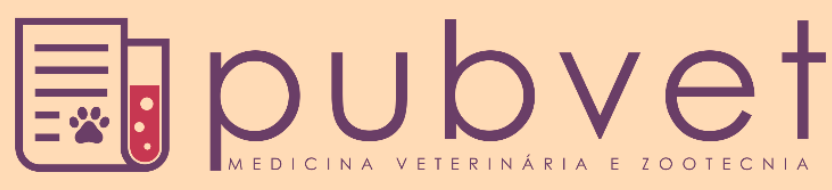

https://doi.org/10.31533/pubvet.v15n03a845.1-11

\title{
Perfil epidemiológico da pandemia de COVID-19 e características do agente etiológico: Revisão
}

\author{
Amanda Barreto Nogueira ${ }^{1}$, Camila Vasconcelos de Sousa Silva ${ }^{10}$, Larissa Melo da Silva ${ }^{10}$, \\ Marcos Roberto Barros Freitas ${ }^{1 *}$, Fabiana Batalha Knackfuss ${ }^{2} \bullet$
}

${ }^{I}$ Discentes do Curso de Medicina Veterinária da Universidade do Grande Rio, Faculdade de Medicina Veterinária. Duque de Caxias - RJ Brasil. ${ }^{2}$ Professora do Curso de Medicina Veterinária da Universidade do Grande Rio, Faculdade de Medicina Veterinária. Duque de Caxias - RJ Brasil. *Autor para correspondência, E-mail: marcos.freitas@unigranrio.br

\begin{abstract}
Resumo. Em 2019, na China, houve um surto de uma pneumonia de etiologia desconhecida. Diante disto, o governo chinês realizou uma investigação epidemiológica para identificação do agente causador, que veio a ser denominado SARS-CoV-2, um novo tipo de coronavírus, causador da enfermidade COVID-19. Os coronavírus fazem parte de uma grande família viral, que recebe esse nome devido às espículas que dão aspecto de coroa. Pertencem à ordem Nidovirales, família Coronaviridae e subfamília Orthocoronavirinae, sendo vírus RNA e assim com maiores predisposições a sofrerem mutações e possuem altos índices de transmissibilidade, com infecções podendo causar desde resfriados comuns até síndromes graves. Estudos evidenciaram uma semelhança de 96\% do SARS-CoV-2 com o BAT-CoV, um coronavírus encontrado em morcegos. A COVID-19 se destacou na saúde pública, devido ao elevado número de casos em um curto período, eventualmente levando a uma pandemia. Na China, nos primeiros 30 dias foram confirmados 11821 casos, com 259 óbitos, e logo após foi constatado que o vírus havia se espalhado não somente na China, mas também em outros países. O tratamento é sintomático, e medidas preventivas preconizam o controle não medicamentoso, como isolamento, distanciamento social, higiene e uso de máscaras. Esta revisão tem como objetivo reunir informações relevantes sobre o agente etiológico e o perfil epidemiológico da enfermidade.
\end{abstract}

Palavras-chave: Coronavírus, covid-19, emergente, pandemia, sars-cov-2

\section{Epidemiological profile of the COVID-19 pandemic and characteristics of it's etiological agent: Review}

\begin{abstract}
In 2019, China, there was a pneumonia outbreak of unknown etiology. Due to this, the chinese government conducted na epidemiological investigation in order to identify the causing agent, that came to be named SARS-CoV-2, a new type of coronavirus, originator of the COVID-19 disease. The coronaviruses are part of a big viral family, named after the viral spike, that resemble a crown. They belong to the Nidovirales order, Coronaviridae family and Orthocoronavirinae subfamily, they are also RNA viruses and thus being more predisposed to suffer mutations and possess high transmissibility rates, and infections being able to cause everything from a mild flu to serious syndromes. Studies have shown a $96 \%$ similarity between SARS-CoV-2 and BAT-CoV, a coronavirus found in bats. COVID-19 stood out in public health, due to the high number of cases in a short time, eventually leading to a pandemic. In China, on the first 30 days, 11821 cases were confirmed, with 259 deaths, and soon after this it was found that the virus had not just spread in China, but in other countries too. The treatment is symptomatic, and preventive measures advocate for non-drug control, like isolation, social distancing, hygiene and
\end{abstract}


wearing masks. This review has the goal to compile relevant information about the etiological agent and the disease's epidemiological profile.

Keywords: Coronavirus, covid-19, emerging, pandemic sars-cov-2

\section{Perfil epidemiológico de la pandemia de COVID-19 y características del agente etiológico: Revisión}

Resumen. En 2019, en China, hubo un brote de neumonía de etiología desconocida. Ante esto, el gobierno chino llevó a cabo una investigación epidemiológica para identificar el agente causante, que pasó a denominarse SARS-CoV-2, un nuevo tipo de coronavirus, que provoca la enfermedad COVID-19. Los coronavirus forman parte de una gran familia viral, que recibe su nombre de los picos que le dan la apariencia de una corona. Pertenecen al orden Nidovirales, familia Coronaviridae, y subfamília Orthocoronavirinae, siendo un virus de ARN y por lo tanto más propensos a mutaciones y tienen altas tasas de transmisibilidad, con infecciones que van desde resfriados comunes hasta síndromes severos. Los estudios han demostrado una similitud de $96 \%$ entre el SARS-CoV-2 y el BAT-CoV, un coronavirus que se encuentra en los murciélagos. La COVID-19 se destacó en salud pública, debido a la gran cantidad de casos en un corto período, que eventualmente desembocaron en una pandemia. En China, en los primeros 30 días se confirmaron 11821 casos, con 259 muertes, y poco después se descubrió que el virus se había extendido no solo en China, sino también en otros países. El tratamiento es sintomático y las medidas preventivas recomiendan en control no farmacológico, como el aislamiento, la distancia social y el uso de mascarillas. Esta revisión tiene como objetivo recopilar información relevante sobre el agente etiológico y el perfil epidemiológico de la enfermedad.

Palabras clave: Coronavirus, covid-19, emergente, pandemia, sars-cov-2

\section{Introdução}

Em dezembro de 2019 na cidade de Wuhan, província de Hubei na China, foram notificados 41 pacientes com sintomatologia respiratória, de etiologia relacionada a um coronavírus até então desconhecido (Huang et al., 2020). O novo coronavírus foi chamado de Wuhan-Hu-1-CoV (Rehman et al., 2020) e 2019-nCoV (Huang et al., 2020), até que foi realizada uma declaração nomeando-o SARSCoV-2 (Gorbalenya et al., 2020), levando em consideração sua filogenia, taxonomia, semelhança com o SARS-CoV e alinhamento com os objetivos de estudo do Comitê Internacional de Taxonomia de Vírus, ICTV.

O SARS-CoV-2 é um vírus RNA, com altos índices de transmissibilidade, e está relacionado ao coronavírus de morcegos (Araujo et al., 2020). É um coronavírus, e por isso envelopado com morfologia baciliforme, pertencente a ordem Nidovirales, família Coronaviridae e subfamília Orthocoronavirinae (ICTV, 2012). Os coronavírus tiveram sua primeira descrição realizada em 1966 e foram considerados por muito tempo patógenos irrelevantes que causavam resfriados comuns até o século 21 onde dois HCoVs (SARS-CoV e MERS-CoV) emergiram com altas morbidade e mortalidade, causando epidemias (Paules et al., 2020). A Organização Mundial da Saúde (2020) publicou em fevereiro observações sobre a enfermidade provocada pelo SARS-CoV-2 e foi decidido que deve se chamar COVID-19, para que assim não se refira a um local geográfico ou grupo de pessoas.

A rápida proliferação do SARS-CoV-2, sua patogenia, mutações e outros mecanismos ainda levantam muitas questões, criando a necessidade de elaboração de diretrizes por parte do governo e autoridades em saúde, e criando uma demanda crescente de informações (Yang et al., 2020). Sendo assim, o objetivo deste trabalho foi revisar a literatura pertinente e reunir informações sobre o agente causador da COVID-19 e seu perfil epidemiológico.

\section{Origem}

A primeira descrição dos Coronavírus foi publicada por Tyrrell and Bynoe (1966) que pelos pacientes apresentando resfriados comuns, cultivaram o vírus. Por muito tempo foram considerados 
patógenos irrelevantes, responsáveis por resfriados banais. Entretanto, no século 21, dois HCoVs altamente nocivos emergiram através de reservatórios animais e causaram epidemias com morbidade e mortalidade preocupantes, são eles o Coronavírus da síndrome respiratória aguda grave (SARS-CoV) e o Coronavírus da síndrome respiratória do Oriente médio (MERS-CoV) (Paules et al., 2020).

No ano de 2019, o governo chinês informou a OMS sobre um surto de pneumonia de etiologia desconhecida. Os casos estavam envolvidos epidemiologicamente com mercado de frutos do mar de Hunan, na cidade de Wuhan, na China, onde animais vivos são rotineiramente vendidos, como morcegos, sapos, cobras, coelhos, pássaros e marmotas (W. Wang et al., 2020). No dia $1^{\text {a }}$ de janeiro de 2020, o mercado de Wuhan foi fechado e iniciou-se um processo de investigação epidemiológica para identificar o agente causador da enfermidade (Lu et al., 2020). Desta maneira, foram selecionados no Hospital de Wuhan três pacientes com pneumonia grave. Pelo fluido bronco alveolar desses pacientes extraiu-se o RNA, que foi usado como modelo para clonagem e sequenciamento de genoma combinando dois métodos. Assim, mais de 20.000 leituras virais foram obtidas em amostras individuais, as quais manifestaram compatibilidade com a linhagem do gênero beta-coronavírus (CoV) (Sifuentes-Rodríguez \& Palacios-Reyes, 2020) e este novo vírus foi denominado de 2019-nCoV (Lu et al., 2020).

Contudo, o conhecimento da origem zoonótica ainda é um dado epidemiológico que vem sendo investigado (Cruz et al., 2020). Todavia, Zhou et al. (2020) descobriram uma curta região de RNA polimerase dependente de RNA (RdRp) de um coronavírus de morcego (BatCov RatG13) que anteriormente foi detectado em Rhinolophus affinis pertencente a província de Yunnan, que possuía uma alta identidade de sequência para 2019-nCoV. Realizaram assim o sequenciamento completo da amostra de RNA. A análise evidenciou que o novo coronavírus é altamente semelhante com o genoma para RaTG13, possuindo uma identidade de sequência genômica geral de 96,2\%. Sendo assim, o morcego é um provável reservatório primário do vírus (Cruz et al., 2020).

\section{Virologia, genética e mutações}

Os coronavírus (CoVs) fazem parte da ordem Nidovirales, família Coronaviridae, subfamília Orthocoronavirinae, são envelopados, com morfologia esférica ou baciliforme e possuem genoma de RNA simples, sentido positivo. (ICTV, 2012). O SARS-CoV-2, especificamente, faz parte do gênero Beta-coronavirus, que também inclui os SARS-CoV-1, MERS-CoV e mais dois outros coronavírus que podem afetar humanos, nomeados HCoV-OC43 e HCoV-HKU1 (Kissler et al., 2020).

ORDEM

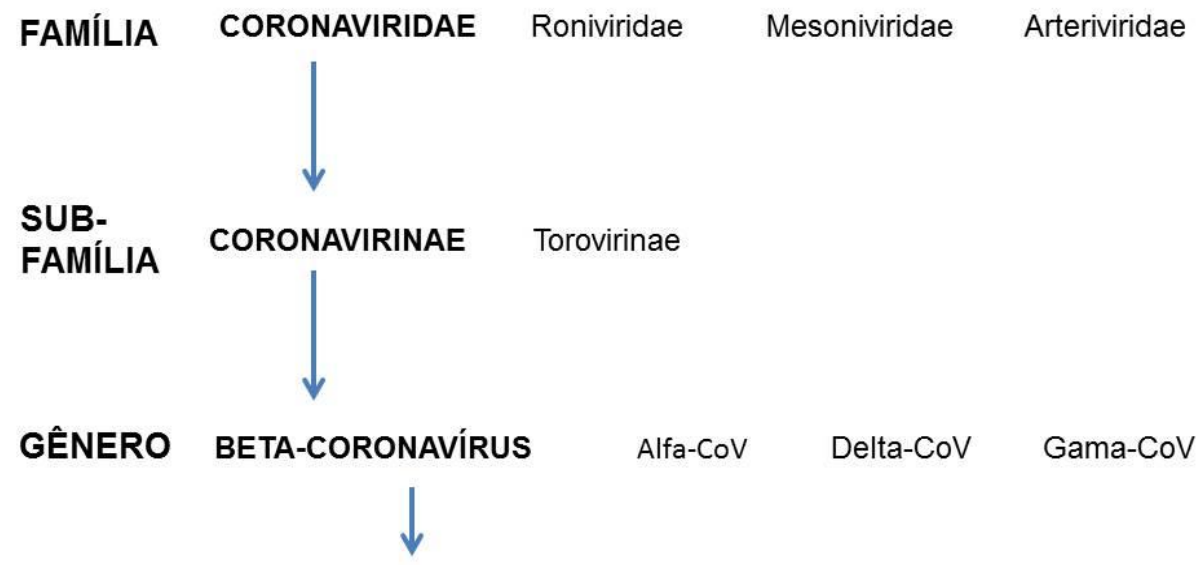

SARS-COV-2, Sars-CoV e Mers-CoV

Figura 1. Classificação do SARS-CoV-2. 
Em janeiro de 2020, seguindo o primeiro protocolo para sequenciamento do vírus pelo RT-PCR publicado por Corman et al. (2020) advieram inúmeros estudos moleculares do vírus. Zhou et al. (2020) constataram via sequenciamento obtido de amostras de cinco pacientes, que o SARS-CoV-2 apresenta 96\% de semelhança genética com um coronavírus encontrado em morcegos, o BatCoV RaTG13, cogitando-se a possibilidade de essa ser a origem do SARS-CoV-2. Da mesma forma, houve 79,6\% de semelhança com o SARS-CoV, que causou surtos de síndrome respiratória aguda 18 anos atrás, e foi confirmado que ambos SARS-CoV-2 e SARS-CoV usam o mesmo receptor para entrada nas células, a enzima conversora de angiotensina 2 (ACE2). Neste mesmo estudo, foi verificado que o genoma do SARS-CoV-2 consiste em seis fases de leitura aberta que são comuns a todos os coronavírus. Posteriormente, foi confirmado por Rehman et al. (2020), que o SARS-CoV-2 de fato descende de coronavírus oriundo de morcegos, sendo os vírus ZXC21 e ZC45 identificados como filogeneticamente mais próximos do SARS-CoV-2. Conjuntamente foi realizada uma comparação entre as proteínas do envelope, capsídeo, membrana e espícula, do SARS-CoV-2 e SARS-CoV, cujos resultados podem ser vistos na tabela 1.

Tabela 1. Homologia entre SARS-CoV-2 e SARS-CoV. Fonte: Rehman et al. (2020).

\begin{tabular}{lccc}
\hline Envelope & Membrana & Nucleocapsídeo & Espícula \\
\hline Homologia $-93 \%$ & Homologia $-92 \%$ & Homologia $-93 \%$ & Homologia $-81 \%$ \\
Variações $-7 \%$ & Variações $-8 \%$ & Variações $-7 \%$ & Variações $-19 \%$ \\
\hline
\end{tabular}

O aumento do número de estudos moleculares sobre o SARS-CoV-2 é de incontestável importância para o esforço global contra a COVID-19. Confirmações laboratoriais de casos de COVID-19 são baseados, em maior parte, em resultados positivos de RT-PCR (Jin et al., 2020). A detecção do RNA viral é de grande valor diagnóstico e deve ser considerado o método padrão para confirmação de casos de COVID-19, como observa-se na diretriz elaborada por Jin et al. (2020), confirmado no estudo clínico realizado por Huang et al. (2020). Uma das maneiras de detectar o SARS-CoV-2 pelo RT-PCR é utilizando iniciador5'-ACTTCTTTTTCTTGCTTTCGTGGT-3', iniciador reverso 5'GCAGCAGTACGCACACAATC-3 e sonda 5'CY5-CTAGTTACACTAGCCATCCTTACTGC3'BHQ1 (uang et al., 2020).

Entretanto, esta não é uma técnica a prova de falhas e ainda não totalmente confiável para este caso, pois como podemos constatar no estudo realizado por Amorim Filho et al. (2020) diversas amostras positivas para anticorpos na sorologia foram testadas em RT-PCR e nenhum resultado positivo foi obtido. Infere-se assim que, apesar do progresso referente aos sequenciamentos, ainda não existe um método definitivo e totalmente confiável para a confirmação dos casos. Reconhecendo as falhas no diagnóstico por meio de detecção do RNA viral em amostras orais, Zhang et al. (2020) testaram a possibilidade do genoma viral ser detectado em amostras anais e de sangue, e obtiveram resultados positivos, sugerindo transmissão por rota orofecal, levantando a hipóteses sobre diversas vias de transmissão do SARS-CoV-2 e evidenciando casos de infectados que carregam o vírus em órgãos além do sistema respiratório.

Vírus com genoma RNA possuem alta taxa de mutação, pois não possuem processo de revisão na atividade das polimerases, fazendo com que esses vírus sejam mais suscetíveis a evoluírem e se tornarem resistentes às drogas e ao sistema imune dos hospedeiros. A taxa de mutação do SARS-CoV-2 ainda é incerta (Shen et al., 2020). Entretanto, justamente por se tratar de um vírus RNA, é de se esperar variantes filogenéticas. É difícil saber a origem exata destas variantes e acompanhar sua filogenia; porém, sabe-se que mutações e transmissões de vários vírus, de seus hospedeiros naturais para humanos são provocadas essencialmente por atividades humanas. A partir de junho de 2020 já existiam mais de 35.000 sequenciamentos disponíveis do SARS-CoV-2 e suas variantes, com potencial para fornecer informações valiosas (Huang et al., 2020). Apesar da quantidade de dados à disposição, ainda não há um sistema definitivo para nomear e discutir sobre as diferentes linhagens filogenéticas, que compõem as diversidades populacionais do vírus (Rambaut et al., 2020). O que é uma ocorrência esperada com o SARS-CoV-2, pois é um vírus recente, e uma taxonomia definitiva referente a qualquer vírus e suas variações filogenéticas é estabelecida apenas quando o vírus em questão e suas variações são exaustivamente caracterizados na literatura, de tal forma que possam ser identificados sem ambiguidade (ICTV, 2018). 
Pensando nesta problemática, com o objetivo de facilitar o esforço em busca da vacina, Rambaut et al. (2020) sugeriram um sistema que contempla novas variantes. Nesta iniciativa, as variantes foram divididas em duas principais linhagens filogenéticas, chamadas linhagem A e linhagem B e suas subdivisões. Ao sequenciar 427 novos genomas, associados a uma base de dados geográfica, Candido et al. (2020) notabilizaram pelo menos por 102 introduções virais internacionais no Brasil, sendo que a maioria das sequências circulando no país pertencem a linhagem B (485/490) e apenas algumas (5/490) pertencem à linhagem $\mathrm{A}$, com presença também de pelo menos três clados virais em território nacional. Neste mesmo trabalho por Candido et al. (2020), estes clados foram caracterizados. O clado brasileiro 1 é caracterizado por uma substituição de nucleotídeos na proteína da espícula viral e circula predominantemente em São Paulo. O clado 2 é caracterizado por duas substituições de nucleotídeos em uma fase de leitura aberta e em uma nucleoproteína e é a sub linhagem mais espalhada pelo país, com presença em diversos estados. O clado 3 é concentrado principalmente no Ceará, sendo o mais próximo das linhagens encontradas na Europa.

Além das diferentes linhagens, houve confirmação também da existência de variantes genéticas intrahospedeiras. Foi encontrada a média de quatro variantes por hospedeiro, em um estudo realizado com amostras de oito pacientes confirmados com COVID-19. Contudo, não foram encontradas evidências de uma possível transmissão destas variantes, apesar da origem destas provavelmente ser mutações in vivo que ocorrem após a infecção, não se pode descartar a possibilidade da mutação pré contágio (Shen et al., 2020). Como a fisio-patogenia da COVID-19, ainda não é muito bem elucidada, foram realizados estudos com o objetivo de analisar prováveis fatores de risco, relacionados ao SARS-CoV-2 e que também possam ser pertinentes a condições dos hospedeiros. Ellinghaus et al. (2020), de um estudo de associação gênica, identificaram um conjunto de genes no cromossomo 3 , locus 3 p21.31, e no cromossomo 9, locus 9q34.2. No cromossomo 3 foi identificado um alelo de risco, que expressa genes nas células pulmonares, e no cromossomo 9 a associação coincidiu com o locus dos grupos sanguíneos $\mathrm{AB}$ 0, supondo um maior risco para indivíduos com tipo sanguíneo A. Posteriormente, contrastando com os resultados anteriores, foi visto que apenas o locus do cromossomo 3 está associado com a sintomatologia severa, e que é conferido por uma sequência genômica de aproximadamente 1.000 pares de bases, que é herdada dos Neandertais e carregada por volta de $50 \%$ da população do Sul da Ásia e $16 \%$ da Europa (Zeberg \& Pääbo, 2020). Aproveitando os numerosos trabalhos de sequenciamento que decorreram, Silva et al. (2020) sugeriram o uso de genética reversa para obter informações relevantes sobre o SARS-CoV-2, referentes por exemplo a expressão gênica, tropismo e marcadores moleculares de virulência.

\section{Evolução do vírus}

Em dezembro de 2019, a cidade de Wuhan, localizada na província de Hubei, na China, vivenciou um surto de pneumonia de causa desconhecida (Heymann \& Shindo, 2020), que posteriormente, pelos cientistas chineses foi identificado como o novo coronavírus (Cheng \& Shan, 2020). Ainda na China, nos primeiros 30 dias, foram registrados 11.821 casos confirmados e 259 óbitos (Cavalcante et al., 2020) em cidades como: Wuhan, Guandong, Beijing (Wang et al., 2020). Em janeiro, houve registro da enfermidade em países da Ásia, Europa e América do Norte, sendo que no dia 21 de janeiro, os Estados Unidos reportaram seu primeiro caso importado da enfermidade (Lana et al., 2020).

Em fevereiro, foi observado um maior alastramento do vírus. Na china, de acordo com a OMS (2020), foram confirmados 74.280 casos com 2.006 óbitos. China afora, foram confirmados de acordo com a OMS, 924 casos, incluindo viajantes de um cruzeiro chamado Diamond Princess. No Brasil, os primeiros casos foram confirmados em fevereiro, e posteriormente foram implementadas diversas ações para tentar impedir o alastramento do vírus (Cavalcante et al., 2020). De 31 de dezembro de 2019 a 16 de maio de 2020 foram registrados 4.425 .485 casos e 302.059 óbitos confirmados por COVID-19 em 216 países e territórios.

Pelos dados acima descritos, é notável a alta capacidade do vírus de se espalhar por entre as cidades e países. A velocidade de propagação de uma enfermidade pode ser avaliada pelo seu número básico de reprodução (R0) definido como o número médio de casos secundários gerados por caso primário (Lana et al., 2020). De acordo com Read et al. (2020) o R0 inicial do SARS-CoV-2 varia de 1,6 a 4,1. Até a data (20/10/2020) de acordo com a OMS há 40.251 .950 casos confirmados com 1.116.131 óbitos. Para 
comparação, a epidemia de Influenza A H1N1 2009 apresentou R0 entre 1,3 e 1,8 Estes dados foram contabilizados a partir do dia 03 de janeiro.

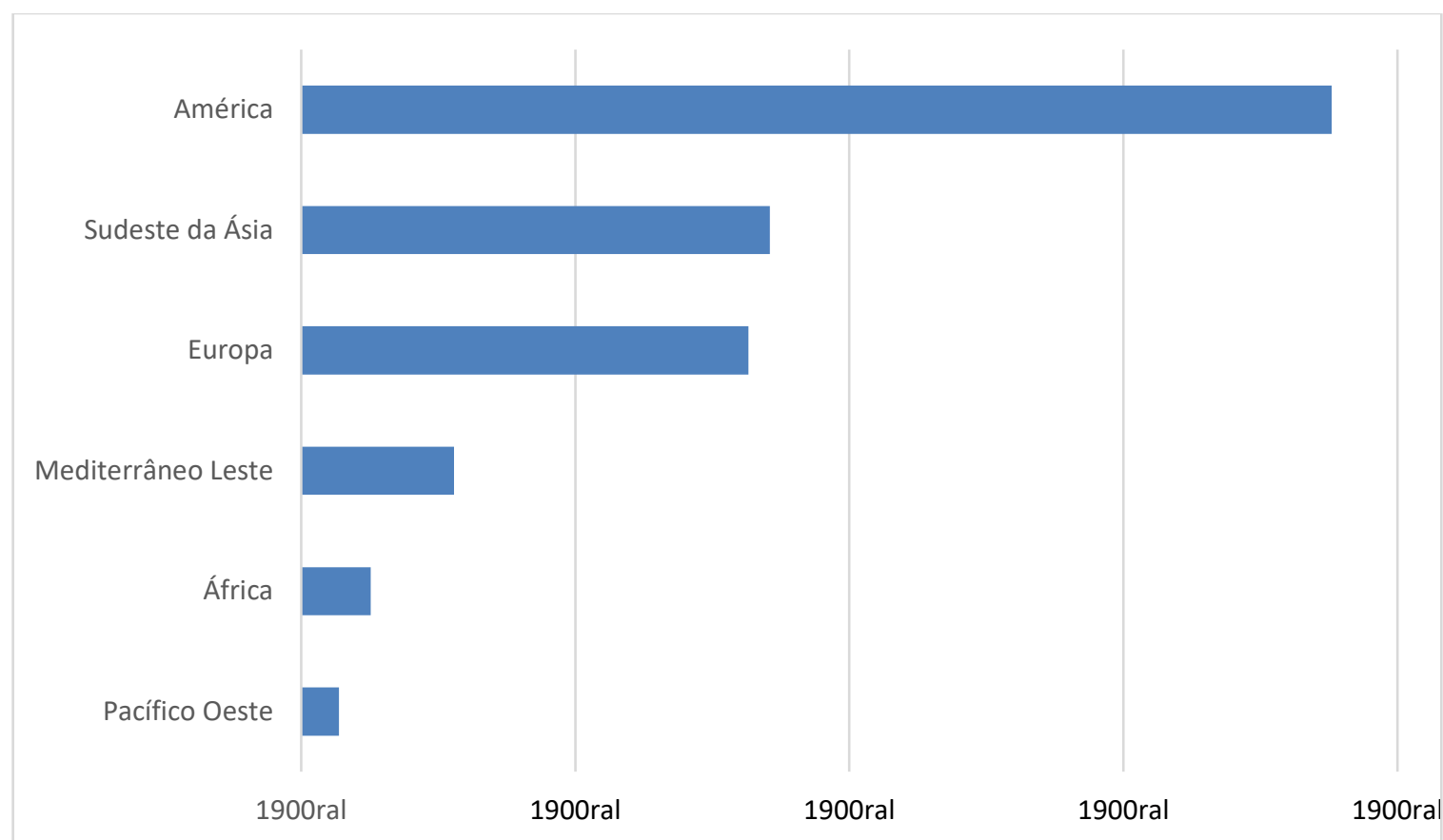

Figura 2. Casos confirmados até o dia 20/10/2020 por região. Fonte: OMS (2020).

\section{Impacto social}

No dia 11 de março de 2020 foi declarado a pandemia de COVID-19 pela OMS (Mello et al., 2020), se apresentando como um desafio totalmente novo para ciência e a sociedade, corroborando com a situação atual que cobra respostas rápidas e diversas do sistema de saúde que precisam ser reorganizados para o enfrentamento da COVID-19 (Medina et al., 2020).

Possuindo uma alta taxa de transmissibilidade, o SARS-CoV-2,não há medicamentos específicos para a cura, as únicas intervenções eficazes e disponíveis para todos no controle da atual pandemia são medidas de saúde pública como isolamento, distanciamento social e vigilância dos casos, apresentando como propósito reduzir o contágio, evitando morte e diminuindo a velocidade com que a pandemia avança (Medina et al., 2020). Entende-se que há uma crise epidemiológica instalada, mas também, não menos importante, uma singular crise econômica que pode se apresentar mais ou menos grave e duradoura, dependendo das medidas emergenciais de políticas econômicas adotadas (Mello et al., 2020).

Discorrendo sobre os impactos sociais no Brasil, em um primeiro momento há o impacto na saúde, afetando principalmente os idosos e indivíduos com enfermidades crônicas não-transmissíveis (DCNT). Em um estudo realizado por Mello et al. (2020) foi caracterizado que 49\% da população é portadora de enfermidades crônicas, sendo que a prevalência tende a aumentar com a idade, atingindo $25 \%$ dos indivíduos com 18 a 24 e $72 \%$ da população com 60 anos ou mais. Entretanto, podemos destacar, que a situação para as pessoas abaixo de 60 anos não é menos alarmante, pois neste grupo $43 \%$ possuem algum fator de risco, como enfermidades crônicas e obesidade, que atingem cerca de $21 \%$ e $20 \%$ dos indivíduos nesta facha etária.

Tudo isto evidencia que o risco de consequências mais graves causadas pela COVID-19 não inclui apenas idosos, atingindo também boa parte da população mais jovem. Outra problemática de suma importância é o diferencial na prevalência de fatores de risco entre os diferentes níveis de escolaridade. Os indivíduos que não possuem o ensino médio, apresentam cerca de $15 \%$ a mais de enfermidades crônicas, tabagismo e obesidade quando comparado com que completaram, nos apresentando que este grupo possui também um maior risco de desenvolver casos mais graves de COVID-19. Juntamente, é de extrema relevância caracterizar a vulnerabilidade dos domicílios onde habitam os brasileiros. Sendo que a falta de acesso a água de qualidade, ao saneamento básico e a alta densidade nos locais de moradia, 
possuem relevante contribuição para a disseminação do vírus, dificultando o isolamento de pessoas com fatores de risco (Roubaud et al., 2020). Assim, foi analisado no mesmo estudo por Roubaud et al. (2020) que cerca de $34 \%$ dos domicílios não possuem saneamento básico ou estrutura adequada e $67 \%$ destes a principal complicação é a falta de escoadouro minimamente adequado de esgoto. E ainda mais alarmante, 54\% dos domicílios brasileiros quatro ou mais pessoas dividem o mesmo banheiro, que em conjunto com uma incidência de fatores de risco maior de $50 \%$ e um grau de informalidade de $20 \%$, o Brasil apresenta uma quadro social preocupante com grandes obstáculos para se fazer o isolamento dos grupos de risco, em grande parte das moradias do país (Roubaud et al., 2020).

O impacto da pandemia no mercado de trabalho pode se apresentar como grande problemática e com uma duração não muito curta. Houve aumento da desocupação, que atinge cerca de 11,9 milhões de pessoas, em consequência da redução da atividade econômica, juntamente com o aumento da pobreza e miséria. Levando em consideração que no trimestre de 2019 a janeiro de 2020 a taxa de informalidade atingiu $40 \%$ da população, representando 38,3 milhões de trabalhadores informais. Sendo que estes estão mais vulneráveis a redução da atividade econômica e, mesmo infectado pelo Sars-CoV-2, podem ser pressionados a continuar a trabalhar para levar sustento as famílias (Mello et al., 2020).

A desigualdade presente no Brasil é um fato que contribui de forma preocupante para disseminação do SARS-CoV-2, causando empecilhos no isolamento social, restringindo o acesso a insumos básicos para higiene e proteção e afetando, até mesmo, a assistência aos serviços de saúde (Minayo \& Freire, 2020). Não sendo uma enfermidade democrática, como muitos pensam, já que as condições de prevenção e cuidado é imposta de forma diferente aos segmentos sociais distintos, como milhões de mulheres, homens e crianças vivendo em situação de rua, que traz como consequência, milhares de pessoas no subemprego dependendo dos movimentos das ruas para conseguir recursos e garantir sua sobrevivência a cada dia. Muitas dessas famílias vivem em casas de um cômodo sem absolutamente nenhum conforto, em ocupações e casarões antigos temendo desabamento ou despejo (Calmon, 2020). Então, deve-se reconhecer que a possibilidade de lavar as mãos com frequência, usar álcool, entre outras recomendações de higiene para a prevenção da pandemia são profundamente complexas de serem adotas quando avaliamos as condições sociais vividas por diversos brasileiros (Farias \& Leite Júnior, 2020). Grande parte dos trabalhadores que compõe os serviços prioritários durante a pandemia, são moradores de periferias e diferentemente dos profissionais de saúde, os serviços prestados por faxineiras, garis, entregadores, empregadas domésticas, trabalhadores de supermercados, motoristas, frentistas de postos, entre outros, não recebem o prestígio que deveriam. E normalmente, essas pessoas dependem das políticas socias ou vivem em situações empregatícias tão frágeis que a negociação com pratões durante a pandemia não é algo possível (Farias \& Leite Júnior, 2020).

Os povos indígenas também fazem parte da população atingida pela COVID-19, e o cenário da entrada desta nova enfermidade nas comunidades pode se apresentar como um grande complicador, pois uma alta porcentagem da população indígena pode ser atingida devido à alta transmissibilidade do SarsCoV-2, vulnerabilidade social de populações isoladas e limitações envolvendo assistência médica e logística de transporte de enfermos. Com a possibilidade de subnotificação e a falta de vigilância dos vetores de dispersão da enfermidade, o controle da transmissão do SARS-CoV-2 pode se tornar uma problemática nestas comunidades, mostrando que as terras indígenas possuem uma alta vulnerabilidade social aos impactos da pandemia (Roubaud et al., 2020).

Assim, é de fácil compreensão que a pandemia tem causado severas mudanças na vida cotidiana da população, atingindo diversos tipos de povos e condições sociais, sendo necessário ser adotadas estratégias, serviços e recursos para prevenção de diversos problemas supracitados (Farias \& Leite Júnior, 2020), para que assim, o impacto dessa inesperada pandemia seja amenizado e que vidas possam ser salvas e não perdidas diante da grande desigualdade presente no país.

\section{Transmissão entre os animais}

Antes de chegar aos humanos, o coronavírus estava presente no meio animal, e para que esta enfermidade chegasse aos Homo sapiens houve uma intermediação dos animais silvestres (Franco \& Bussmann, 2020). O morcego (ordem Chiroptera) e o pangolin (Pholidota) são amplamente estudados hoje, pois são os principais suspeitos da origem deste vírus. Hoje, temos testes laboratoriais que demonstram que o SARS-CoV-2, cepa causadora da COVID-19, tem provável origem em morcegos do 
gênero Rhinolophus (Franco \& Bussmann, 2020). Por terem um sistema imune peculiar e diferenciado, os morcegos quase não são acometidos ou podem até mesmo serem imunes à diversas enfermidades. Estes animais, também são hospedeiros primários de diversas enfermidades como, por exemplo, o vírus Nipah (Li et al., 2005). As atividades destes mamíferos na natureza contribuem muito para o equilíbrio ecológico do planeta. Por serem voadores e terem uma gama de espécies frugívoras. Estes animaistêm um papel crucial para a dinâmica de florestas tropicais por serem os principais dispersores de sementes de plantas pioneiras na região neotropical (Nowak \& Paradiso, 1983). Devido a esta atividade, acreditase que algum animal infectado pelo vírus SARS-CoV-2 pode ter levado pela excreta fecal e resíduo salivar nas sementes o patógeno para a área onde habitam e proximidades. Contudo, estas áreas também são habitadas pelos pangolins, que frequentemente procuram abrigo em cavidades de rochas, no solo, em troncos ocos e entradas de cavernas, locais que também são usados pelos morcegos como moradia. Esse compartilhamento de hábitat pode ter favorecido o spillover do coronavírus dos morcegos aos pangolins (Acosta et al., 2020).

\section{Transmissão para humanos}

Como supracitado, o SARS-CoV-2 é oriundo de animais silvestres, mas adquiriu a capacidade de saltar entre diferentes espécies - incluindo a habilidade de infectar humanos por meio de um processo chamado spillover (Acosta et al., 2020). O tráfico de animais silvestres é algo muito comum atualmente, seja este tráfico para cativeiro seja para o consumo. Os pangolins, por exemplo, são considerados um dos animais mais traficados do planeta, sendo a China o maior financiador deste tráfico (Acosta et al., 2020). Esse consumo, ou contato de sua carne crua com outros alimentos, tem sido apontado como fatores facilitadores ao spillover da cepa que deu origem a SARS-CoV-2 (Liu et al., 2020). Esta mesma ideia segue para os morcegos, mas para estes, pode ter ocorrido também a transmissão direta, apesar de ser mais raro e menos provável do que o spillover a partir de outro animal (Plowright et al., 2017). O "mercado úmido", Huanan na cidade de Wuhan, tem sido apontado como marco zero dessa pandemia, pelo fato de lá serem vendidos animais vivos em meio ao comércio de frutos do mar, de carnes variadas, incluindo animais silvestres como morcegos, pangolins, roedores e outros potenciais hospedeiros de coronavírus, mas também porque mais da metade das pessoas inicialmente diagnosticadas com COVID19 estiveram nesse mercado (Huang et al., 2020).

\section{Transmissão entre humanos}

Sabe-se que diversas enfermidades são transmitidas por contato direto (beijos, lambeduras, mordeduras) e também indireto (fômites). Em razão disso a higiene pessoal deve ser muito valorizada e ensinada no controle da pandemia. Durante surtos anteriores de coronavírus MERS e SARS a transmissão homem-a-homem ocorreu por gotículas, contato e fômites sugerindo que o modo de transmissão do COVID-19 pode ser semelhante (Pimentel et al., 2020). Diversas enfermidades hoje podem ser evitadas se houver um maior cuidado com a higiene pessoal. Simples hábitos como lavar a mão corretamente, não levar alimentos não higienizados à boca, evitar colocar a mão suja no rosto, entre outros são atitudes que são capazes de evitar a contaminação por diversos patógenos.

Com o SARS-CoV-2, este pensamento não é diferente, a transmissão deste vírus acontece entre humanos, podendo ocorrer de pessoa a pessoa pelo ar, por meio de tosse ou espirro, pelo toque ou aperto de mão ou pelo contato com objetos ou superfícies contaminadas, seguido pelo contato com a boca, nariz ou olhos (Pimentel et al., 2020). Com estas informações, é nítida a importância que os preceitos da promoção de saúde, práticas de higiene devem ser reforçados diariamente para a população (Pimentel et al., 2020), sendo importante que estas informações cheguem para todas as classes sociais e que estas tenham acesso à uma melhor sanidade. Transmissão oral-fecal é possível (devido presença de ECA2 no trato gastrointestinal e presença de PCR-TR positivo em amostra de fezes). Contudo, ainda não foi documentada (Tang et al., 2020). Há relatos também de possível transmissão vertical intrauterina no terceiro trimestre, com neonato assintomático apresentando elevação de citocinas e IgM positivo (Dong et al., 2020).

\section{Considerações finais}

Pelas considerações vistas nesta revisão, foi possível concluir que os patógenos vindos de reservatório animal são de extrema importância para a saúde pública, causando impactos muitas das 
vezes irreparáveis. Com isso, entende-se que a pandemia de COVID-19 trouxe um alerta, evidenciando principalmente a importância do médico veterinário na Saúde pública, visto que o inicio dos casos vieram de um mercado de frutos do mar de Hunan, onde são vendidos animais vivos sem uma fiscalização eficiente. A pandemia também evidenciou ainda mais a desigualdade social presente no Brasil, onde nem todos puderam passar por esta fase da melhor maneira, tendo que escolher entre respeitar a quarentena ou trabalhar para garantir a renda familiar.

\section{Referências}

Acosta, A. L., Xavier, F., Chaves, L. S. M., Sabino, E. C., Saraiva, A., \& Sallum, M. A. M. (2020). Interfaces à transmissão e spillover do coronavírus entre florestas e cidades. Estudos Avançados, 34(99), 191-208. https://doi.org/10.1590/S0103-4014.2020.3499.012.

Amorim Filho, L., Szwarcwald, C. L., Mateos, S. de O. G., Leon, A. C. M. P., Medronho, R. de A., Veloso, V. G., Lopes, J. I. F., Porto, L. C. de M. S., Chieppe, A., \& Werneck, G. L. (2020). Seroprevalence of anti-SARS-CoV-2 among blood donors in Rio de Janeiro, Brazil. Revista de Saúde Pública, 54, 54-69.

Araujo, L. F. S., Strina, A., Grassi, M. F. R. G., \& Teixeira, M. G. (2020). Aspectos clínicos e terapêuticos da infecção da COVID-19. Universidade Federal da Bahia/Fundação Oswaldo Cruz.

Calmon, T. V. L. (2020). As condições objetivas para o enfrentamento ao COVID-19: abismo social brasileiro, o racismo, e as perspectivas de desenvolvimento social como determinantes. NAU Social, 11(20), 131-136. https://doi.org/10.9771/ns.v11i20.36543.

Candido, D. S., Claro, I. M., Jesus, J. G., Souza, W. M., Moreira, F. R. R., Dellicour, S., Mellan, T. A., Du Plessis, L., Pereira, R. H. M., \& Sales, F. C. S. (2020). Evolution and epidemic spread of SARSCoV-2 in Brazil. Science, 369(6508), 1255-1260.

Cavalcante, J. R., Cardoso-dos-Santos, A. C., Bremm, J. M., Lobo, A. P., Macário, E. M., Oliveira, W. K., \& França, G. V. A. (2020). COVID-19 en Brasil: evolución de la epidemia hasta la semana epidemiológica 20 de 2020. Epidemiologia e Serviços de Saúde, 29(4), e2020376.

Cheng, Z. J., \& Shan, J. (2020). 2019 Novel coronavirus: where we are and what we know. Infection, 48(2), 155-163. https://doi.org/10.1007/s15010-020-01401-y.

Corman, V., Bleicker, T., Brünink, S., Drosten, C., \& Zambon, M. (2020). Diagnostic detection of 2019nCoV by real-time RT-PCR. World Health Organization, 17, 1-13.

Cruz, M. P., Santos, E., Cervantes, M. A. V., \& Juárez, M. L. (2020). COVID-19, a worldwide public health emergency. Revista Clínica Española, 55-61. https://doi.org/10.1016/j.rce.2020.03.001.

Dong, L., Tian, J., He, S., Zhu, C., Wang, J., Liu, C., \& Yang, J. (2020). Possible vertical transmission of SARS-CoV-2 from an infected mother to her newborn. JAMA - Journal of the American Medical Association, 323(18), 1846-1848. https://doi.org/10.1001/jama.2020.4621.

Ellinghaus, D., Degenhardt, F., Bujanda, L., Buti, M., Albillos, A., Invernizzi, P., Fernández, J., Prati, D., Baselli, G., Asselta, R., Grimsrud, M. M., Milani, C., Azis, F., Kässens, J., May, S., Wendorff, M., \& Wienbrandt, L. (2020). Genomewide association study of severe Covid-19 with respiratory failure. New England Journal of Medicine, 383(16), 1522-1534. https://doi.org/10.1056/nejmoa2020283.

Farias, M. N., \& Leite Júnior, J. D. (2020). Vulnerabilidade social e Covid-19: considerações a partir da terapia ocupacional social. Cadernos Brasileiros de Terapia Ocupacional, 1(1), 1-15.

Franco, F. M., \& Bussmann, R. W. (2020). Rising to the occasion: outlining Ethnobiologists' response to the coronavirus (COVID-19) pandemic. Ethnobotany Research and Applications, 20, 1-4. https://doi.org/10.32859/era.20.06.1-4.

Gorbalenya, A. E., Baker, S. C., Baric, R., Groot, R. J. de, Drosten, C., Gulyaeva, A. A., Haagmans, B. L., Lauber, C., Leontovich, A. M., \& Neuman, B. W. (2020). Severe acute respiratory syndromerelated coronavirus: The species and its viruses-a statement of the Coronavirus study group. BioRxiv - The Preprint Server ForBiology. https://doi.org/10.1101/2020.02.07.937862.

Heymann, D. L., \& Shindo, N. (2020). COVID-19: what is next for public health? Lancet, 395, 542545. https://doi.org/10.1016/S0140-6736(20)30374-3. 
Huang, C., Wang, Y., Li, X., Ren, L., Zhao, J., Hu, Y., Zhang, L., Fan, G., \& Xu, J. (2020). Clinical features of patients infected with 2019 novel coronavirus in Wuhan, China. The Lancet, 395, 497506. https://doi.org/10.1016/S0140-6736(20)30183-5.

ICTV - International Committee on Taxonomy of Viruses. (2012). Virus Taxonomy - Classification and Nomenclature of Viruses.

ICTV - International Committee on Taxonomy of Viruses. (2018). The international code of virus classification and nomenclature.

Jin, Y.-H., Cai, L., Cheng, Z.-S., Cheng, H., Deng, T., Fan, Y.-P., Fang, C., Huang, D., Huang, L.-Q., \& Huang, Q. (2020). A rapid advice guideline for the diagnosis and treatment of 2019 novel coronavirus (2019-nCoV) infected pneumonia (standard version). Military Medical Research, 7(1), 1-23. https://doi.org/10.11855/j.issn.0577-7402.2020.01.01.

Kissler, S. M., Tedijanto, C., Goldstein, E., Grad, Y. H., \& Lipsitch, M. (2020). Projecting the transmission dynamics of SARS-CoV-2 through the postpandemic period. Science, 368(6493), 860 868. https://doi.org/10.1101/2020.03.04.20031112.

Lana, R. M., Coelho, F. C., Gomes, M. F. C., Cruz, O. G., Bastos, L. S., Villela, D. A. M., \& Codeço, C. T. (2020). Emergência do novo coronavírus (SARS-CoV-2) e o papel de uma vigilância nacional em saúde oportuna e efetiva. Cadernos de Saúde Pública, 36(3), e00019620. https://doi.org/10.1590/0102-311x00019620.

Li, W., Shi, Z., Yu, M., Ren, W., Smith, C., Epstein, J. H., Wang, H., Crameri, G., Hu, Z., \& Zhang, H. (2005). Bats are natural reservoirs of SARS-like coronaviruses. Science, 310(5748), 676-679. https://doi.org/10.1126/science.1118391.

Liu, P., Jiang, J.-Z., Wan, X.-F., Hua, Y., Li, L., Zhou, J., Wang, X., Hou, F., Chen, J., \& Zou, J. (2020). Are pangolins the intermediate host of the 2019 novel coronavirus (SARS-CoV-2)? PLoS Pathogens, 16(5), e1008421. https://doi.org/10.1371/journal.ppat.1008421.

Lu, R., Zhao, X., Li, J., Niu, P., Yang, B., Wu, H., Wang, W., Song, H., Huang, B., \& Zhu, N. (2020). Genomic characterisation and epidemiology of 2019 novel coronavirus: implications for virus origins and receptor binding. The Lancet, 395(10224), 565-574. https://doi.org/10.1016/S01406736(20)30251-8.

Medina, M. G., Giovanella, L., Bousquat, A., Mendonça, M. H. M., \& Aquino, R. (2020). Atenção primária à saúde em tempos de COVID-19: o que fazer? Cadernos de Saúde Pública, 36, e00149720. https://doi.org/10.1590/0102-311x00149720.

Mello, G., Oliveira, A. L. M., Guidolin, A. P., Caso, C., David, G., \& Nascimento, J. C. (2020). A coronacrise: natureza, impactos e medidas de enfrentamento no Brasil e no mundo. In Nota do Cecon (Vol. 9, pp. 1-23). n.

Minayo, M. C. S., \& Freire, N. P. (2020). The pandemic exacerbates health inequalities. Ciência \& Saúde Coletiva, 25, 3555-3556. https://doi.org/10.1590/1413-81232020259.13742020.

Nowak, R. M., \& Paradiso, J. L. (1983). Walker's mammals of the world. The Johns Hopkins University Press.

OMS - Organização Mundial da Saúde (2020). Timeline: WHO's COVID-19 response. https://www.who.int/emergencies/diseases/novel-coronavirus-2019/interactive-timeline.

Paules, C. I., Marston, H. D., \& Fauci, A. S. (2020). Coronavirus infections-more than just the common cold. AMA - Journal of the American Medical Association, 323(8), 707-708. https://doi.org/10.1001/jama.2020.0757.

Pimentel, R. M. M., Daboin, B. E. G., Oliveira, A. G., \& Mecedo Júnior, H. (2020). A disseminação da covid-19: um papel expectante e preventivo na saúde global. Journal of Human Growth and Development, 30(1), 135-140.

Plowright, R. K., Parrish, C. R., McCallum, H., Hudson, P. J., Ko, A. I., Graham, A. L., \& Lloyd-Smith, J. O. (2017). Pathways to zoonotic spillover. Nature Reviews Microbiology, 15(8), 502-510. https://doi.org/10.1038/nrmicro.2017.45.

Rambaut, A., Holmes, E. C., O’Toole, Á., Hill, V., McCrone, J. T., Ruis, C., du Plessis, L., \& Pybus, O. G. (2020). A dynamic nomenclature proposal for SARS-CoV-2 lineages to assist genomic 
epidemiology. Nature Microbiology, 5(11), 1403-1407. https://doi.org/10.1101/2020.04.17.046086.

Read, J. M., Bridgen, J. R. E., Cummings, D. A. T., Ho, A., \& Jewell, C. P. (2020). Novel coronavirus 2019-nCoV: early estimation of epidemiological parameters and epidemic predictions. MedRxiv. https://doi.org/10.1101/2020.01.23.20018549.

Rehman, S., Shafique, L., Ihsan, A., \& Liu, Q. (2020). Evolutionary trajectory for the emergence of novel coronavirus SARS-CoV-2. Pathogens, 9(3), 240. https://doi.org/10.3390/pathogens9030240.

Roubaud, F., Razafindrakoto, M., Saboia, J. L. M., dos Reis Castilho, M., \& Pero, V. (2020). The municipios facing COVID-19 in Brazil: Socioeconomic vulnerabilities, transmisssion mechanisms and public policies. UMR LEDa.

Shen, Z., Xiao, Y., Kang, L., Ma, W., Shi, L., Zhang, L., Zhou, Z., Yang, J., Zhong, J., \& Yang, D. (2020). Genomic diversity of severe acute respiratory syndrome-coronavirus 2 in patients with coronavirus disease 2019. Clinical Infectious Diseases, 71(15), 713-720. https://doi.org/10.1093/infdis/jiaa229.

Sifuentes-Rodríguez, E., \& Palacios-Reyes, D. (2020). COVID-19: The outbreak caused by a new coronavirus. Boletin Medico Del Hospital Infantil de Mexico, 77(2), 47-53. https://doi.org/10.24875/BMHIM.20000039,

Silva, S. J. R., Mendes, R. P. G., Silva, C. T. A., Lorusso, A., Kohl, A., \& Pena, L. (2020). Insights into SARS-CoV-2, the Coronavirus underlying COVID-19: recent genomic data and the development of reverse genetics systems. The Journal of General Virology, 101(10), 1021. https://doi.org/10.1099/jgv.0.001458.

Tang, A. N., Tong, Z., Wang, H., Dai, Y., Li, K., Liu, J., Wu, W., Yuan, C., Yu, M., \& Li, P. (2020). Detection of novel coronavirus by RT-PCR in stool specimen from asymptomatic child, China. Emerging Infectious Diseases, 26(6), 1337-1339. https://doi.org/10.3201/EID2606.20.0301.

Tyrrell, D. A. J., \& Bynoe, M. L. (1966). Cultivation of viruses from a high proportion of patients with colds. Lancet, 1(748), 76-77. https://doi.org/10.1016/s0140-6736(66)92364-6.

Wang, C., Horby, P. W., Hayden, F. G., \& Gao, G. F. (2020). A novel coronavirus outbreak of global health concern. The Lancet, 395(10223), 470-473. https://doi.org/10.1016/S0140-6736(20)30185-9.

Wang, W., Tang, J., \& Wei, F. (2020). Updated understanding of the outbreak of 2019 novel coronavirus (2019-nCoV) in Wuhan, China. Journal of Medical Virology, 92(4), 441-447. https://doi.org/10.1002/jmv.25689.

Yang, X., Yu, Y., Xu, J., Shu, H., Liu, H., Wu, Y., Zhang, L., Yu, Z., Fang, M., \& Yu, T. (2020). Clinical course and outcomes of critically ill patients with SARS-CoV-2 pneumonia in Wuhan, China: a single-centered, retrospective, observational study. The Lancet Respiratory Medicine, 8(5), 475-481. https://doi.org/10.1016/S2213-2600(20)30079-5.

Zeberg, H., \& Pääbo, S. (2020). The major genetic risk factor for severe COVID-19 is inherited from Neanderthals. Nature, 587(7835), 610-612. https://doi.org/10.1101/2020.07.03.186296.

Zhang, W., Du, R.-H., Li, B., Zheng, X.-S., Yang, X.-L., Hu, B., Wang, Y.-Y., Xiao, G.-F., Yan, B., \& Shi, Z.-L. (2020). Molecular and serological investigation of 2019-nCoV infected patients: implication of multiple shedding routes. Emerging Microbes \& Infections, 9(1), 386-389. https://doi.org/10.1080/22221751.2020.1729071.

Zhou, P., Yang, X.-L., Wang, X.-G., Hu, B., Zhang, L., Zhang, W., Si, H.R., Zhu, Y., Li, B., \& Huang, C.-L. (2020). A pneumonia outbreak associated with a new coronavirus of probable bat origin. Nature, 579(7798), 270-273. https://doi.org/10.1038/s41586-020-2012-7.

Histórico do artigo:

Recebido: 12 de janeiro de 2021 .

Aprovado: 20 de fevereiro de 2021.
Licenciamento: Este artigo é publicado na modalidade Acesso Aberto sob a licença Creative Commons Atribuição 4.0 (CC-BY 4.0), a qual permite uso irrestrito, distribuição, reprodução em qualquer meio, desde que o autor e a fonte sejam devidamente creditados. 